\section{Worried Sick. A Prescription for Health in an Overtreated America}

Nortin M. Hadler, Chapel Hill: University of North Carolina Press, 2008, 392 pages, US $\$ 28.00$

Hadler is Prometheus, fortunately not having to sacrifice his liver to feed the vulture. He wrote this book for the laiety, but it behooves physicians to read it. Although Hobbes described human life as solitary, poor, nasty, brutish, and short, it needn't be that; for the readers of this book who take his message to heart it won't: They will spend less on treatments that don't work for diseases that are ephemera and medicines that are income-producers for the industry, but of little or no avail to life expectancy and comfort assurance. Many complaints are ephemeral; they don't need medical attention, but when the latter is sought, they become diseases, and medicines and treatments are offered. That symptoms would resolve anyway, that relative risks make them sound ominous but absolute risks are small, that we have been medicalized to a fare-thee-well, and that our life spans are finite should be obvious to most people. And it is to the public at large — not just to physicians - that this book is directed.

In fact, the public is the intended audience. For most complaints, there are few remedies (remember, we are not talking of actual diseases, but chiefly of those so-called diseases that are the results of life's stresses): So we are importuned on all sides by the purveyors of prescription medicines, but even more so by those who would have us take the unregulated nutraceuticals, not to mention unnecessary surgery (most backaches). To listen to football coaches and iceskaters (Hadler's favorite advertising villains), we are constantly beset by a vast array of diseases, and should ask our doctors whether such-and-such a product is right for us. Unfortunately, our doctors are subjected to the same propaganda mill as the laiety, so overmedicalization goes on apace. Hadler is almost a nihilist when it comes to most diseases, but choice of death is not an idle exercise: Some deaths are more painful or more premature than others. Still, an informed public eschews the blandishments of eternal and pain-free life, and the readers of this book are urged to exercise their judgment.

I am not convinced that eschewing most laboratory tests is sound practice, but slight deviations from the norm probably do not deserve treatment, especially as any effective medicine probably carries with it some serious adverse effects in some of those who take it. And remember, normality is a range, and perhaps age-related in many instances! The gold that glitters is in the pockets of those who would convince you otherwise. Many of us live our lives under a pall, so it should not surprise us that the body resists. Fibromyalgia, chronic fatigue syndrome, and other similar non-diseases are responses to life's stresses, but are a source of income for the uninformed and venal physicians and pharmaceutical hucksters. Bogus studies support their claims. Run for the hills if someone whose help you sought thinks that medications or surgery will heal these responses to stress, or labels complaints with contrived names that sound like illnesses!

Yes, this is an important book. While I cannot agree with every assertion, on the whole, the reader will understand symptoms and their causation and will be richer for it - intellectually and in pocket. I recommend it for all would-be patients and for those called upon to treat them.

GEORGE E. EHRLICH, MD, Adjunct Professor of Medicine, University of Pennsylvania, Philadelphia PA, USA.

J Rheumatol 2009;36:2; doi:10.3899/jrheum.081166 